\title{
Evaluation of a strict protocol approach in managing women with severe disease due to hypertension in pregnancy: A before and after study
}

\author{
Hennie Lombaard*1, Robert C Pattinson ${ }^{1}$, Fèbè Backer ${ }^{1}$ and \\ Peter Macdonald ${ }^{2}$
}

\begin{abstract}
Address: ${ }^{1}$ Department of Obstetrics and Gynaecology, Kalafong Hospital, Private Bag X396, Pretoria 0001, South Africa and ${ }^{2}$ MRC Maternal and Infant Health Care Strategies Research Unit and Obstetrics and Gynaecology Department, University of Pretoria, South Africa

Email: Hennie Lombaard* - hennie.lombaard@up.ac.za; Robert C Pattinson - rcpattin@kalafong.up.ac.za; Fèbè Backer - febe.backer@up.ac.za; Peter Macdonald - petermac@med.up.ac.za

* Corresponding author
\end{abstract}

Published: 30 September 2005

Reproductive Health 2005, 2:7 doi:10.1 186/1742-4755-2-7
Received: 03 May 2005

Accepted: 30 September 2005

This article is available from: http://www.reproductive-health-journal.com/content/2/I/7

(c) 2005 Lombaard et al; licensee BioMed Central Ltd.

This is an Open Access article distributed under the terms of the Creative Commons Attribution License (http://creativecommons.org/licenses/by/2.0), which permits unrestricted use, distribution, and reproduction in any medium, provided the original work is properly cited.

\begin{abstract}
Background: To evaluate whether the introduction of a strict protocol based on the systemic evaluation of critically ill pregnant women with complications of hypertension affected the outcome of those women.

Method: Study group: Indigent South African women managed in the tertiary hospitals of the Pretoria Academic Complex. Since 1997 a standard definition of women with severe acute maternal morbidity (SAMM), also referred to as a Nearmiss, has been used in the Pretoria Academic Complex. All cases of SAMM and maternal deaths (MD) were entered on the Maternal Morbidity and Mortality Audit System programme (MaMMAS). A comparison of outcome of severely ill women who had complications of hypertension in pregnancy was performed between 1997-I 998 (original protocol) and 2002-2003 (strict protocol). Data include women referred from outside the Pretoria Academic Complex area to the tertiary hospitals.
\end{abstract}

Results: Between 1997-1998 there were 79 women with SAMM and 18 maternal deaths due to complications of hypertension, compared with 91 women with SAMM and 13 maternal deaths in 2002-2003. The mortality index (MI) declined from I8.6\% to I2.5\% (OR $0.62,95 \% \mathrm{Cl} 0.27-\mathrm{I} .45$ ). Statistically significant fewer women had renal failure (RR $0.37,95 \% \mathrm{Cl} 0.21-0.66)$ and cerebral complications (RR $0.52,95 \% \mathrm{Cl} 0.34-0.8 \mathrm{I}$ ) during the second period, and liver dysfunction (RR $0.2795 \% \mathrm{Cl} 0.06-1.25)$ tended to be lower. However, there tended to be an increase in the number of women, who had immune system failure (RR $4.295 \% \mathrm{Cl} 0.93-18.94)$ and respiratory failure (RR I.42 95\% Cl $0.88-2.29)$ although it did not reach significance. Cardiac failure remained constant (RR $0.8495 \% \mathrm{Cl} 0.54-1.30$ ).

Conclusion: The strict protocol approach based on the systemic evaluation of severely ill pregnant women with complications of hypertension and an intensive, regular feedback mechanism has been associated with a reduction in the number of patients with renal failure and cerebral compromise. 


\section{Background}

Complications due to hypertensive disease in pregnancy are the most common direct cause of maternal death (MD) in South Africa [1,2]. They are also the most common cause of acute severe morbidity in a survey of three clearly defined geographical areas in South Africa [3]. The final and contributory causes of deaths were most commonly cerebral complications (40\% and 50\%), cardiac failure $(40 \%$ and $35 \%)$, respiratory failure $(15 \%$ and $16 \%)$ and renal failure (10\% and 18\%) in 1998 and 1999-2001 respectively [1,2]. Any strategy for improving the outcome of severely ill pregnant women with complications due to hypertension would have to address ways of preventing these organ systems from failing.

In 1997, the Pretoria Academic Complex initiated the use of a standard definition of severe acute maternal morbidity (SAMM) [4] and the routine collection of data since. Table 1 shows the definition for organ system dysfunction for each specific organ system. After the initial survey in 1997-1998, protocols were reviewed and a new approach to managing severely ill pregnant women was introduced. This system was based on the systematic routine evaluation of all organ systems and, where an abnormality was detected, this served as a trigger to further investigate and support that organ system [5]. This policy was adopted for managing critically ill pregnant women with specific common conditions and as a group became known as "the strict protocols".

The implementation of new policies can be difficult to achieve [6]. The change in policy was effected by regular reinforcement at daily audit meetings at the individual hospitals and weekly departmental meetings where all cases of SAMM and MD were discussed. New trainees were introduced to the protocols from the start, face-to-face meetings were held when problems were detected, and special training sessions were introduced to stress specific points. Finally, a report was compiled and presented to the provincial administration with specific recommendations appropriate to the region. There has been ongoing regular contact since then.

This study examines the effect of the introduction of this strict protocol on the outcome of critically ill pregnant women with complications of hypertension in pregnancy and attempts to identify where further research or change in policy is required.

\section{Methods}

The Pretoria Academic Complex consists of two academic hospitals (Pretoria Academic and Kalafong) and two district hospitals (Mamelodi Day and Pretoria West). The area receives referrals from other areas within Gauteng Province and the surrounding provinces. The Pretoria Aca- demic Complex serves a population of 3 million people. The population served is mainly an indigent general South African population. The female population was 554 000 in 1996 with an annual growth of 10\%, the fertility rate for Gauteng is $2.3 \%$ for women aged 15 to 49 and the current pregnancy rate is $2.2 \%$ [17]. The number of births within the immediate area has increased by twenty percent over the last five years and is currently approximately 15000 per year. For the period of $1997 / 1998$, the total number of births was 27 025, the maternal mortality ratio was $133.2 / 100000$ births and the perinatal mortality rate was $37 / 1000$ for babies weighing more than 1000 gr. For the period of 2002/2003 the total number of births was 32814 , the maternal mortality ratio was $115.8 / 100000$ births and the perinatal mortality rate for babies weighing more than 1000 gr was 27/1000 births.

The criteria for SAMM have been defined by Mantel et al. [4] as a woman with organ system dysfunction or failure who would probably have died if un- or inadequately treated. The criteria are based on clinical evaluation with limited specific investigations that are readily available at all regional, secondary and higher level hospitals.

Data on women with SAMM and MD were collected every morning at the respective hospitals and a near miss form was completed for each woman with SAMM and the maternal death notification form for all maternal deaths. The data were entered into the Maternal Morbidity and Mortality Audit System (MaMMAS) database, developed by Johan Coetzee (Simply Software). Data from 1997/ 1998 (initial project) [3] served as the platform for developing the database. This initial project compared Maternal Mortality and Nearmiss to determine if disease pattern was the same. In the second time period (2002/2003) the strict protocol had been implemented and became established.

Standard statistical techniques were used to compare the two time periods. The chi square test was used to compare categorical data. The outcome measures were the Mortality Index, defined as the number of maternal deaths divided by the sum of women with SAMM and maternal deaths, expressed as a percentage [7]. The criteria for each organ system dysfunction/failure were specified in the definition of a woman with SAMM [4] and the rates of each organ system dysfunction were compared between the two time periods. The relative risk was used to compare the two time periods as it gives a more realistic indication of the changes.

During the first time period $(1997 / 1998)$ there was no strict protocol available and standard care was provided. This consisted of magnesium sulphate for eclamptic fits and hydralazine 1,25 mg ivi every $15 \mathrm{~min}$ for the acute 
Table I: The criteria for a near-miss case for each specific organ system according to Mantel.

\begin{tabular}{|c|c|}
\hline Organ system-based & Markers \\
\hline Cardiac dysfunction & $\begin{array}{l}\text { Pulmonary oedema } \\
\text { Cardiac arrest }\end{array}$ \\
\hline Vascular dysfunction & Hypovolaemia requiring $\geq 5$ units of blood products \\
\hline Immunological dysfunction & $\begin{array}{l}\text { ICU admission for sepsis } \\
\text { Emergency hysterectomy for sepsis }\end{array}$ \\
\hline Respiratory dysfunction & $\begin{array}{l}\text { Intubation and ventilation for any reason other than general anaesthesia } \\
\text { Oxygen saturation of less than } 90 \% \text { for more than } 60 \mathrm{~min} \\
\text { The ratio of the partial pressure of oxygen in arterial blood to the percentage oxygen in inspired air is } \leq 3 \text { ( } \mathrm{paO} 2 / \\
\mathrm{FiO} 2 \leq 3 \text { ) }\end{array}$ \\
\hline Renal dysfunction & $\begin{array}{l}\text { Oliguria, } \leq 400 \mathrm{ml} / 24 \mathrm{hr} \text { that does not respond to careful fluid replacement or attempts at inducing with dopamine } \\
\text { or infusion } \\
\text { Acute deterioration in urea }>15 \mathrm{mmol} / \mathrm{l} \text { or of creatinine to }>400 \mathrm{mmol} / \mathrm{l}\end{array}$ \\
\hline Liver dysfunction & Jaundice in the presence of pre-eclampsia \\
\hline Metabolic dysfunction & Diabetic keto-acidosis \\
\hline Coagulation dysfunction & Acute thrombocytopenia requiring a platelet transfusion \\
\hline Cerebral dysfunction & $\begin{array}{l}\text { Coma lasting }>12 \text { hours } \\
\text { Subarachnoid or intracerebral haemorrhage }\end{array}$ \\
\hline
\end{tabular}

Table 2: Summary of stabilising the severely ill women with complications of Hypertension after admission to a High Care Obstetrics unit

\begin{tabular}{|c|c|c|c|}
\hline Organ system & Acute management & Maintenance & Management of complications \\
\hline Fluid management & $\begin{array}{l}\text { Start IV line give } 300 \mathrm{ml} \text { fluid bolus: } \\
100 \mathrm{ml} \text { Ringers lactate } \\
200 \mathrm{ml} \text { normal saline with loading } \\
\text { dose of magnesium sulphate Urinary } \\
\text { Catheter }\end{array}$ & $\begin{array}{l}\text { Give Ringers lactate } 125 \mathrm{ml} / \mathrm{hr} \text { iv. } \\
\text { Start a fluid balance chart }\end{array}$ & $\begin{array}{l}\text { If poor output repeat fluid bolus. If } \\
\text { still poor output and positive fluid } \\
\text { balance start low-dose dopamine } \\
\text { infusion }\end{array}$ \\
\hline Magnesium Sulphate & $\begin{array}{l}4 \mathrm{~g} \text { magnesium sulphate in } 200 \mathrm{ml} \\
\text { saline over } 20 \text { min iv } \\
5 \mathrm{~g} \text { magnesium sulphate with I ml } \\
\text { lignocaine im in each buttock }\end{array}$ & $\begin{array}{l}\text { Maintenance: } 5 \mathrm{~g} \text { four hourly iv } \\
\text { Check before next dosage: Urine } \\
\text { output }>30 \mathrm{ml} / \mathrm{hr} \\
\text { Tendon reflexes present } \\
\text { Respiratory rate more than } 16 / \mathrm{min}\end{array}$ & $\begin{array}{l}\text { In case of magnesium sulphate } \\
\text { overdose give calcium gluconate }\end{array}$ \\
\hline Blood pressure control & $\begin{array}{l}\text { Repeat blood pressure after } 20 \text { min } \\
\text { and if diastolic } \geq 110 \text { or systolic } \geq 160 \\
\text { treat according to the } \\
\text { antihypertensive drug protocol }\end{array}$ & Use either nifedipine or labetolol & \\
\hline Neurological status & $\begin{array}{l}\text { If still confused check saturation and } \\
\text { blood pressure }\end{array}$ & $\begin{array}{l}\text { Abnormal saturation: Give oxygen via } \\
\text { mask } \\
\text { Abnormal blood pressure: treat with } \\
\text { appropriate drugs }\end{array}$ & If both are normal: give haloperidol \\
\hline
\end{tabular}

treatment of hypertension if the diastolic BP was $\geq 110$ mmHg. A fluid balance chart was not routinely kept and the management of the patient was mainly based on the opinion of the attending consultant.

In contrast, the strict management protocol, implemented during the second time period (2002/2003) included the following:

\section{Stabilization}

The stabilization of the patient is summarised in Table 2.

\section{Systemic Evaluation}

Table 3 summarizes the systemic evaluation of the mother.

\section{Foetal Evaluation}

An ultrasonographic evaluation of the foetus was performed, once the mother had been stabilised, and included the following:

- Estimated foetal weight

- Doppler of the umbilical artery

- Amniotic fluid index 
Table 3: Summary of the systemic evaluation and special investigations of critical ill women with complications of hypertension

\begin{tabular}{|c|c|c|}
\hline Organ system evaluated & Clinical examination & Special investigations \\
\hline Central nervous system & $\begin{array}{l}\text { Glasgow coma scale } \\
\text { Lateralising signs } \\
\text { Reflexes } \\
\text { Pupil reflexes }\end{array}$ & If any abnormalities consider CT Scan \\
\hline Respiratory system & $\begin{array}{l}\text { Respiratory rate } \\
\text { Blood gas } \\
\text { Check for dullness on percussion, crepitations or wheezes }\end{array}$ & If any abnormalities do blood gas and Chest X-ray \\
\hline Cardiovascular system: & $\begin{array}{l}\text { Pulse, Blood pressure } \\
\text { Heart sounds } \\
\text { Heart size } \\
\text { Radio-femoral delay }\end{array}$ & \\
\hline Gastro intestinal system: & Check for epigastric tenderness, hepatomegaly & $\begin{array}{l}\text { Check AST and for jaundice. } 4 \text { hourly blood glucose test if } \\
\text { raised AST }\end{array}$ \\
\hline Renal system: & $\begin{array}{l}\text { Check for renal angle tenderness, macroscopic hematuria } \\
\text { Listen for murmurs over the renal artery }\end{array}$ & $\begin{array}{l}\text { Check creatinine and fluid balance. If signs of kidney } \\
\text { dysfunction do full kidney function tests }\end{array}$ \\
\hline Haematological system: & Check for anaemia, purpera, bleeding tendency & Check hematocrit and platelets \\
\hline Immune system: & $\begin{array}{l}\text { Body temperature } \\
\text { Check for generalized lymphadenopathy, splenomegaly, } \\
\text { signs of immune system failure }\end{array}$ & $\begin{array}{l}\text { Voluntary counselling and HIV testing if CD4 and ESR } \\
\text { above } 100\end{array}$ \\
\hline Musculosceletal System & $\begin{array}{l}\text { Check for signs of DVT } \\
\text { Check for spinal problems that might influence the type of } \\
\text { anaesthesia }\end{array}$ & \\
\hline Gynaecological system: & $\begin{array}{l}\text { Abdominally: measure symphysis-fundus height, lie \& } \\
\text { position of the foetus, check for uterine tenderness or } \\
\text { contractions, estimate foetal weight, measure amniotic } \\
\text { fluid, check for foetal heart rate } \\
\text { Vaginal exam: assess the Bishop score }\end{array}$ & \\
\hline Fundoscopy: & $\begin{array}{l}\text { Check for silver wiring, papillar oedema and signs of } \\
\text { bleeding }\end{array}$ & \\
\hline
\end{tabular}

- Transcerebellar diameter

- Middle cerebral artery Doppler

- Ductus venosus waveform

- Detection of possible structural abnormalities

If the expected foetal weight was more than $800 \mathrm{~g}$ or the foetus was known to have a gestational age of 28 weeks or more, the foetus was regarded as viable. In these cases corticosteroids were administered and the foetal heart rate pattern was monitored six hourly with a cardiotocograph (CTG).

After all this information had been gathered a management plan was formulated. In most cases the laboratory blood results (initially only aspartate-amino transferase (AST), creatinine, haematocrit and platelets) were available within the hour and during the stabilisation phase of the patient. To make a final decision four questions needed to be answered by the clinician, namely:

1. Is it safe for the mother to continue the pregnancy?

2. Is it safe for the foetus to continue the pregnancy?
3. What is the risk to neonate if the foetus was born?

4. What is the risk to the mother if the foetus was born?

In case of expectant management, the woman was transferred to a high care (high dependency unit) obstetric unit, with daily evaluation by the registrar and routine blood testing (haematocrit, platelets, creatinine and AST) twice weekly. Cardiotocogram (CTG) (6 hourly) and ultrasound (two-weekly) were used to assess foetal wellbeing and growth. If there was concern about foetal growth, ultrasound was repeated more often [10].

The indications for delivery were:

- Foetal distress

- Intra uterine death

- Expected birth weight more than $2 \mathrm{~kg}$

- Expected birth weight less than $500 \mathrm{~g}$

- Maternal organ system failure

- Uncontrollable hypertension 


\section{- Eclampsia}

- Proven foetal lung maturity

- Foetal abnormality

The indications for elective caesarean section were:

- Unfavourable Bishop score (4 or less)

- Foetal distress as diagnosed on the basis of spontaneous decelerations on CTG

- Absent end diastolic flow of the uterine artery on Doppler

- An abnormal ductus venosus waveform. The ductus venosus wave form was regarded as abnormal if it was absent or reversed.

\section{Antihypertensive drug protocol}

Alpha methyldopa was used as the first line oral antihypertensive agent [10] (an initial dose of $500 \mathrm{mg} 8$ hourly was used increasing to a maximum of $750 \mathrm{mg} 8$ hourly). In cases of severe hypertension (blood pressure more than $160 \mathrm{mmHg}$ systolic or $110 \mathrm{mmHg}$ diastolic) $10 \mathrm{mg}$ nifedipine [11] was administered orally. Nifedipine (10 mg) has replaced dihydralazine in the strict protocol as it is more effective in controlling blood pressure and is safer for the foetus $[11,12]$. If the blood pressure remained higher than 160/110 $\mathrm{mmHg}$ after one hour a repeat dose of nifedipine was given. If the woman was unable to swallow or had a tachycardia of more than 120 beats per minute, labetolol [13] was administered: the patient was started with $20 \mathrm{mg}$ iv and if the blood pressure remained above 160/110 $\mathrm{mmHg}$ after $10 \mathrm{~min}$ she would receive 40 $\mathrm{mg}$ iv. If her blood pressure still remained above 160/110 $\mathrm{mmHg}$ she would receive $80 \mathrm{mg}$ iv. This would be repeated another two times 10 minutes apart if needed.

\section{Fluid management}

After admission to the High Care Obstetric Unit, the woman was maintained on $125 \mathrm{ml} / \mathrm{hr}$ Ringers lactate intravenously. A strict input and output chart was recorded by the nursing staff. The attending registrar regularly determined the fluid balance taking into account insensible and blood loss. If the patient was excreting less than $30 \mathrm{ml}$ per hour and was in a negative balance a 300 ml Ringers lactate bolus was administered. If the patient had positive fluid balance a low dose dopamine infusion was started [9].

\section{Ethical considerations}

The Ethics Committee of the Faculty of Health Sciences gave approval for the initial study and the programme remains registered with the Ethics Committee. The hospital administration at each hospital continues to give approval for the audit. Patient information is anonymised once entered into the database.

\section{Results}

In $1997 / 1998$ there were 27,025 births in the Pretoria Academic Complex and 32,814 births in 2002/2003, an increase of $21.4 \%$. This excludes all referrals and patients born in private institutions. The Maternal Mortality Ratio (MMR) for indigent patients from the Pretoria area, dying from complications of hypertension in pregnancy remained unchanged with 9 deaths in 1997/1998 (MMR $33.3 / 100000$ births) and 8 deaths in 2002/2003 (MMR $24.4 / 100000$ births). However the prevalence of women severely ill from complications of hypertension in pregnancy in our population rose from 40 patients $(0.15 \%)$ in $1997 / 1998$ to 64 patients $(0.20 \%)$ in $2002 / 2003$. The denominators for referred patients are unknown.

Auditing all patients with complicated hypertension demonstrated that in 1997/1998 there were 79 SAMM and a further 18 maternal deaths compared to 91 women with SAMM and 13 maternal deaths in 2002/2003. The distribution of age and parity in both groups was similar: age less than 20 years ( $11 \%$ and $9.6 \%), 20$ to 29 years $(50.6 \%$ and $52.8 \%), 30$ to 39 years (28.9\% and $31.7 \%)$ and primigravid (42.3\% and $43.2 \%)$.

Table 4 compares the distribution of the different categories of women with severe complications of hypertension in pregnancy. Statistically significantly more women had severe complications following eclampsia during 1997/ 1998 compared to 2002/2003, but the opposite was true for women with severe complications following HELLP syndrome. It is important to note that the diagnosis of eclampsia or HELLP syndrome does not automatically classify a woman as having severe morbidity as there also has to be organ system dysfunction as defined above. Overall, the Mortality Index declined from $18.6 \%$ in $1997 / 1998$ to $12.5 \%$ in $2002 / 2003$ (Odds Ratio 0.62, 95\% CI 0.27-1.45). There were no differences in Mortality Indices within the individual disease categories.

Table 5 compares the organ system dysfunction/failure for severely ill pregnant women with complications of hypertension. Significantly fewer women had renal failure $(34.0 \%$ vs $12.5 \%$, RR $0.37,95 \%$ CI $0.21-0.66)$ and cerebral complications (35.1\% vs $14.4 \%$, RR 0.52 95\%CI 0.34 - 0.81 ) than before, and liver dysfunction (7.2\% vs $1.9 \%$, RR $0.2795 \%$ CI 0.06 - 1.25) tended to be lower. However, there was a trend towards an increase in number of women who had immune system failure $(2.0 \%$ to $8.7 \%$, RR $4.295 \%$ CI 0.93 - 18.94) and respiratory failure $(21.6 \%$ to $30.8 \%$, RR $1.4295 \%$ CI $0.88-2.29)$ in the sec- 
Table 4: Comparison between the sub-categories of complications of hypertension in pregnancy and their Mortality Indices.

\begin{tabular}{|c|c|c|c|c|c|c|c|c|c|c|c|}
\hline & \multicolumn{5}{|c|}{$1997-1998$} & \multicolumn{5}{|c|}{$2002-2003$} & \multirow[t]{2}{*}{$\mathbf{p} \mathbf{M I}$} \\
\hline & MD & SAMM & Total & $\%$ & MI & MD & SAMM & Total & $\%$ & MI & \\
\hline Chronic Hypertension & 1 & 2 & 3 & 3.1 & 33.3 & 1 & 4 & 5 & 4.8 & 20.0 & \\
\hline Proteinuric Hypertension & 6 & 22 & 28 & 28.9 & 21.4 & 4 & 30 & 34 & 32.7 & 11.8 & 0.49 \\
\hline Eclampsia* & 9 & 38 & 47 & 48.5 & 19.1 & 6 & 22 & 28 & 26.9 & 21.4 & 0.52 \\
\hline HELLP** & 2 & 17 & 19 & 19.6 & 10.5 & I & 35 & 36 & 34.6 & 2.8 & 0.27 \\
\hline Liver rupture & 0 & 0 & 0 & 0.0 & 0.0 & 1 & 0 & I & 1.0 & 100.0 & \\
\hline All Hypertension & 18 & 79 & 97 & 100 & 18.5 & 13 & 91 & 104 & 100 & 12.5 & 0.32 \\
\hline
\end{tabular}

MD - Maternal Death; SAMM - Severe acute maternal morbidity; MI - Mortality Index

* - Significant decline in proportion of eclampsia from $1997 / 8$ to 2002/3, $\mathrm{p}=0.0026$

** - Significant increase in proportion of women with HELLP syndrome $1997 / 8$ to $2002 / 3, p=0.026$

Table 5: Comparison of the prevalence of organ system dysfunction/failure per severely ill pregnant women with complications due to hypertension.

\begin{tabular}{|c|c|c|c|c|c|c|c|c|c|}
\hline \multirow[t]{2}{*}{ Organ system } & \multicolumn{4}{|c|}{$1997-1998$} & \multicolumn{4}{|c|}{ 2002-2003 } & \multirow[t]{2}{*}{$\operatorname{RR}(95 \% \mathrm{Cl})$} \\
\hline & $\begin{array}{c}\text { SAMM } \\
\mathrm{n}=79\end{array}$ & $\begin{array}{l}\text { MD } \\
\mathrm{n}=18\end{array}$ & $\begin{array}{l}\text { SAMM+M } \\
\text { D N = 97 }\end{array}$ & $\%$ OSD & $\begin{array}{l}\text { SAMM } \\
N=91\end{array}$ & $\begin{array}{l}\text { MD } \\
N=13\end{array}$ & $\begin{array}{l}\text { SAMM+M } \\
\text { D N = } 104\end{array}$ & $\%$ OSD & \\
\hline Hypovolaemic shock & 7 & 1 & 8 & 8.2 & 5 & 1 & 6 & 5.8 & $0.7(0.25-1.94)$ \\
\hline Respiratory failure & 17 & 4 & 21 & 21.6 & 29 & 3 & 32 & 30.8 & $1.42(0.88-2.29)$ \\
\hline Cardiac failure & 25 & 5 & 30 & 30.9 & 23 & 4 & 27 & 26.0 & $0.84(0.54-1.30)$ \\
\hline Renal failure & 29 & 4 & 33 & 34.2 & 11 & 2 & 13 & 12.5 & $0.37(0.21-0.66)$ \\
\hline Liver failure & 5 & 2 & 7 & 7.2 & 1 & I & 2 & 1.9 & $0.27(0.06-1.25)$ \\
\hline Cerebral complications & 24 & 10 & 34 & 35.1 & 9 & 6 & 15 & 14.4 & $0.52(0.34-0.8 I)$ \\
\hline Haematological dysfunction & 25 & 4 & 29 & 29.9 & 26 & 1 & 27 & 26.0 & $0.87(0.56-1.36)$ \\
\hline Immune system failure* & I & 1 & 2 & 2.1 & 6 & 3 & 9 & 8.7 & $4.2(0.93-18.94)$ \\
\hline
\end{tabular}

\% OSD - Percentage of severely ill women who developed that organ system dysfunction/failure

Note: A patient can have more than one organ system dysfunction/failure

* Fisher exact: 2 sided 0.060

: I sided 0.038

ond period compared to the first although it did not reach significance. Cardiac failure remained constant $(30.9 \%$ and $26.0 \%$ RR 0.84 95\%CI $0.54-1.30$ ).

The average number of organ systems that failed or were dysfunctional for all critically ill women were 1.69 in $1997 / 1998$ and 1.25 in 2002/2003. This indicates that per critically patient there were less severely compromised organ systems in the second period compared to the first.

Table 6 examines the patients that came from the Pretoria area only. The pattern of organ system dysfunction/failure was the same but the numbers were too small to have sufficient power to detect significant differences. The Mortality Index in Pretoria for 1997/1998 was $22.5 \%$ and $12.5 \%$ for 2002/2003 (OR 0.49, 95\% CI 0.15-1.57).

\section{Discussion}

This report of managing critically ill pregnant women with complications of hypertension in pregnancy during two time periods five years apart has shown a change in pattern of organ system dysfunction/failure. Fewer women developed renal failure and cerebral complications during the later time period. However, other common complications of the respiratory, cardiovascular and immune systems did not seem to be affected by the implementation of the strict protocol.

The possible explanations for the change are better identification of patients with complications and better management, and fewer referrals of critically ill patients from outside areas. By increasing the number of cases identified with improved surveillance, one would have expected a sudden increase in the rate of critically ill women being treated followed by a levelling off. However, there has been a steady increase in the rate from $84 / 100000$ births in $1999,108 / 100000$ births in 2000 and $138 / 100000$ births in 2001 [14]. 
Table 6: Comparison of the prevalence of organ system dysfunction/failure per severely ill pregnant women with complications due to hypertension for patients only from the Pretoria area.

\begin{tabular}{|c|c|c|c|c|c|c|c|c|}
\hline \multirow[t]{2}{*}{ Organ system } & \multicolumn{4}{|c|}{ 1997-1998 } & \multicolumn{4}{|c|}{$2002-2003$} \\
\hline & $\begin{array}{l}\text { SAMM } \\
\mathrm{n}=31\end{array}$ & $\begin{array}{l}\text { MD } \\
n=9\end{array}$ & $\begin{array}{c}\text { SAMM+MD } \\
N=40\end{array}$ & $\%$ OSD & $\begin{array}{l}\text { SAMM } \\
N=56\end{array}$ & $\begin{array}{l}M D \\
N=8\end{array}$ & $\begin{array}{c}\text { SAMM+MD } \\
N=64\end{array}$ & $\%$ OSD \\
\hline Hypovolaemic shock & 2 & 0 & 2 & 5.0 & 3 & 1 & 4 & 6.3 \\
\hline Respiratory failure & 7 & 3 & 10 & 25.0 & 16 & 2 & 18 & 28.1 \\
\hline Cardiac failure & 12 & 4 & 16 & 40.0 & 13 & 3 & 16 & 25.0 \\
\hline Renal failure & 6 & 1 & 7 & 17.5 & 5 & 1 & 6 & 9.4 \\
\hline Liver failure & 0 & 0 & 0 & 0.0 & 1 & I & 2 & 3.1 \\
\hline Cerebral complications & 8 & 4 & 12 & 30.0 & 4 & 3 & 7 & 10.9 \\
\hline Haematological dysfunction & 9 & 1 & 10 & 25.0 & 19 & I & 20 & 31.3 \\
\hline Immune system failure & 0 & 1 & 0 & 2.5 & 2 & 2 & 4 & 6.3 \\
\hline
\end{tabular}

\% OSD - Percentage of severely ill women who developed that organ system dysfunction/failure

Note: A patient can have more than one organ system dysfunction/failure

The reduction in critically ill patients referred from outside the Pretoria area could also account for the change in our findings. The longer time to get into a tertiary unit is likely to increase the severity of the complications. Thus the shift from $61 \%$ of critically ill women being referred in $1997 / 1998$ as opposed to only $48 \%$ in $2002 / 2003$ could account for the change. Examining only the cases from the Pretoria area (Table 6), the same shift in pattern is seen although the number of cases was too few to detect significant changes.

The final explanation is that the management of the patients has improved. This is supported by the decreased number of dysfunctional organ systems per patient; it fell from 1.69 in $1997 / 1998$ to 1.25 in $2002 / 2003$. This change may be associated with the introduction and adherence to a strict protocol for managing such critically ill women. It is postulated that using the strict protocol may have prevented further organ systems from becoming involved. The strict protocol was based on the audit in $1997 / 1998$ and the introduction of treatment research findings such as the use of magnesium sulphate for women with severe pre-eclampsia [8]. The feedback system of regular audit meetings to discuss cases, one by one meetings and regular teaching sessions to discuss specific issues confirms the success found in previous randomised trials [6]. The rapid turnover of staff necessitates regular reinforcement of protocols.

One of the limitations of our study was that we used a 'before and after' design to evaluate the effect of the implementation of a strict protocol with no control patients in any of the time periods. Further, the study could not explain the fact that there was no reduction in cardiac and respiratory problems.
The lack of change in the respiratory and cardiovascular system organ dysfunction/failure suggests that there is still significant room for improving the protocol. The confidential enquiries into maternal deaths in the UK revealed that $37 \%$ of maternal deaths due to eclampsia or preeclampsia during the 1985-1999 period are being ascribed to "pulmonary" [15]. Adult respiratory distress syndrome has been described as contributing factor in $28 \%$ [16] of deaths associated with HELLP syndrome. Cardiac and respiratory functions in severe pre-eclampsia are not well understood and future research must attempt to identify the changes that can improve the outcome. The increasing incidence of HIV infection in the area accounts for the rise in immune system failure. This may also affect pulmonary and cardiac function.

The 33\% increase of women who were critically ill due to complications of hypertension from the Pretoria area is disturbing. The reason for this is unknown. There has been a steady influx of people into the Gauteng area during the last 5 years. This is confirmed by the 2001 Census [17] and the increase of more than twenty percent of births in the Pretoria area. This influx of many impoverished people looking for employment would be expected to bring more unhealthy people to the region. This will lead to increased pressure on the primary health care services to identify these patients early (at antenatal clinics) and refer appropriately, and increase the pressure on secondary and tertiary services that must deal with the increased load of critically ill patients. Appropriate plans for distribution of resources need to be made to deal with this challenge.

\section{Conclusion}

The strict protocol approach based on the systemic evaluation of critically ill pregnant women due to complications of hypertension has been associated with a 
reduction in the preventable complications, such as renal failure and cerebral compromise by improved fluid management and blood pressure control. However, there has been no change in the prevalence of cardiac or respiratory failure. Cardiac and respiratory function in women with severe hypertension in pregnancy needs further investigation and strategies need to be developed to improve its management.

\section{List of Abbreviations}

SAMM: Severe acute maternal morbidity

MaMMAS: Maternal Morbidity and Mortality Audit System programme

MD: Maternal Deaths

AIDS: Acquired Immune Deficiency Syndrome

HELLP: Haemolysis, Elevated Liver Enzymes, Low Platelets

AST: Aspartate-amino transferase

UK: United Kingdom

OR: Odds Ratio

MMR: Maternal Mortality Ratio

CTG: Cardio tochography

\section{Competing interests}

The author(s) declare that they have no competing interests.

\section{Authors' contributions}

RCP and PM wrote the initial protocol and coordinated the collection of the SAMM data. FB entered the data on the MaMMAS programme. HL and FB collected the results from the MaMMAS programme. HL, FB and RCP did the statistical analysis. HL wrote the article. RCP and PM substantially improved the manuscript.

\section{Acknowledgements}

DrJ Makin help with the statistical analysis of the study. Mrs Sue Sellers and Dr SS Smith helped with editing the article.

\section{References}

I. Moodley J, Nyasulu D: Hypertensive disorders of pregnancy. In Saving Mothers: Report on confidential enquiries into maternal deaths in South Africa, 1998 Edited by: Pattinson RC. Government Printer, Pretoria; 1999:28-39.

2. Moodley J, Molefe N: Hypertensive disorders of pregnancy. In Saving Mothers 1999-200I: Second report on confidential enquiries into maternal deaths in South Africa Edited by: Pattinson RC. Government Printer, Pretoria; 2003:37-54.
3. Pattinson RC, Buchmann EJ, Mantel G, Schoon M, Rees H: Can enquiries into severe acute maternal morbidity act as a surrogate for maternal death enquiries? BJOG 2003, I 1 0:889-893.

4. Mantel GD, Buchmann E, Rees H, Pattinson RC: Severe acute maternal morbidity: a pilot study of a definition for a nearmiss. BJOG 1998, 105:985-990.

5. Pattinson RC, Mantel G: A systematic approach to examining an ill pregnant woman. In Saving Mothers: Policy and management guidelines for common causes of maternal deaths Edited by: Moodley J. Government Printer; 2001:6-23.

6. Grimshaw JM, Shirran L, Thomas R, et al:: Changing provider behaviour: An overview of systematic reviews of interventions. Medical Care 200I, 39(supplement 2):II-2-II-45.

7. Vandecruis H, Pattinson RC, Macdonald AP: Changing patterns of severe acute maternal morbidity and mortality in the Pretoria Region. Eur J Obstet Gynaecol Reprod Biol 2002, 102:6-10.

8. The Magpie Collaborative Group: Do women with pre-eclmpsia, and their babies, benefit from magnesium sulphate? The Magpie Trail: A randomised placebo controlled trail. The Lancet 2002, 359:1877-90.

9. Mantel GD, Makin JD: Low dose Dopamine in postpartum preeclamptic women with oliguria: a double-blind, placebo controlled, randomised trail. BJOG 1997, 104: ||80-1|83.

10. Hall DR, Odendaal HJ, Steyn DW: Expectant management severe pre-eclampsia in the mid-trimester. European J Obstet Gynecol Reprod Biol 200I, 96:168-172.

II. Smith P, Anthony J, Johnson R: Nifedipine in pregnancy. BJOG 2000, 107:299-307.

12. Hall DR, Odendaal HJ, Steyn DW, Smith M: Nifedipine or prazosin as a second agent to control early severe hypertension in pregnancy: a randomised controlled trial. BJOG 2000, 107:759-765.

13. Collins R, Duley L: Labetolol vs hydralazine in severe pregnancy induced hypertension. In Pregnancy and Childbirth Module of the Cochrane Database of Systemic Reviews Edited by: Enkin MW, Keirse MJNC, Renfrew MJ, Neilson JP. BMJ Publishing group, London; 1995.

14. Pattinson RC, Hall M: Near Misses. A useful adjunct to maternal mortality audits. Br Med Bull 2003, 67:23I-243.

15. Drife J, Lewis G, editors: Why Mothers Die. In Confidential Enquiries into Maternal Deaths in the United Kingdom 1997-1999 London: RCOG Press; 200I.

16. Isler CM, Rinehart BK, Terrone DA, Martin RW, Magam EF, Martin JN: Maternal mortality associated with HELLP (hemolysis, elevated liver enzymes, and low platelets) syndrome. Am J Obstet Gynecol 1999, 181:924-8.

17. Lehohla P: Census 200I. Census in Brief. Second edition. Published Statistics South Africa; 2003.

Publish with Bio Med Central and every scientist can read your work free of charge

"BioMed Central will be the most significant development for disseminating the results of biomedical research in our lifetime. "

Sir Paul Nurse, Cancer Research UK

Your research papers will be:

- available free of charge to the entire biomedical community

- peer reviewed and published immediately upon acceptance

- cited in PubMed and archived on PubMed Central

- yours - you keep the copyright 